Supplementary Information:

\title{
What Affects the Quartet-Doublet Energy Splitting in Peroxidase
}

\author{
Enzymes? \\ Sam P. de Visser* \\ School of Chemical Engineering and Analytical Science, The University of Manchester, Sackville Street, P.O. \\ Box 88, Manchester M60 1QD, United Kingdom.
}


Table S1. Relative energies, group spin densities $(\rho)$ and group charges $(Q)$ of low-lying electronic states of Cpd I and Cpd II of CcP as calculated with Jaguar using UB3LYP/LACVP.

\begin{tabular}{|c|c|c|c|c|c|c|c|c|c|c|c|c|c|}
\hline State & $\Delta E^{\mathrm{a}}$ & $\rho_{\mathrm{Fe}}$ & $\rho_{\mathrm{O}}$ & $\rho_{\text {Por }}$ & $\rho_{\mathrm{ImH}}$ & $\rho_{\text {Asp }}$ & $\rho_{\operatorname{Trp}}$ & $Q_{\mathrm{Fe}}$ & $Q_{\mathrm{O}}$ & $Q_{\text {Por }}$ & $Q_{\mathrm{ImH}}$ & $Q_{\text {Asp }}$ & $Q_{\operatorname{Trp}}$ \\
\hline${ }^{4} \mathrm{~A}_{2 \mathrm{u}}{ }^{\mathrm{b}}$ & 0.00 & 1.01 & 1.05 & 0.44 & 0.01 & 0.01 & 0.48 & 0.61 & -0.27 & -0.15 & 0.17 & -0.67 & 0.31 \\
\hline${ }^{2} \mathrm{~A}_{2 \mathrm{u}}{ }^{\mathrm{b}}$ & 0.13 & 1.04 & 1.03 & -0.59 & 0.02 & -0.01 & -0.49 & 0.61 & -0.27 & -0.16 & 0.17 & -0.67 & 0.32 \\
\hline${ }^{4} \mathrm{~A}_{1 \mathrm{u}}$ & 6.87 & 1.02 & 1.04 & 0.80 & 0.00 & 0.00 & 0.14 & 0.62 & -0.27 & 0.16 & 0.17 & -0.70 & 0.02 \\
\hline${ }^{2} \mathrm{~A}_{1 \mathrm{u}}$ & 4.15 & 1.03 & 1.04 & -0.56 & -0.01 & 0.00 & -0.50 & 0.61 & -0.27 & -0.16 & 0.15 & -0.68 & 0.35 \\
\hline${ }^{3} \Pi$ & $-85.70^{c}$ & 1.06 & 1.01 & -0.06 & -0.01 & 0.00 & 0.00 & 0.60 & -0.30 & -0.60 & 0.15 & -0.73 & -0.12 \\
\hline
\end{tabular}

${ }^{a}$ in kcal mol ${ }^{-1} \cdot{ }^{b}$ Orbital occupation: $\pi^{*}{ }_{\mathrm{xz}}{ }^{1} \pi^{*}{ }_{\mathrm{yz}}{ }^{1}\left(\mathrm{a}_{2 \mathrm{u}}+\pi_{\mathrm{Trp}}\right)^{1}{ }^{c}-85.70 \mathrm{kcal} \mathrm{mol}^{-1}=3.72 \mathrm{eV}$.

Table S2. Relative energies, group spin densities $(\rho)$ and group charges $(Q)$ of low-lying electronic states of Cpd I and Cpd II of CcP as calculated with Jaguar using UB3LYP/LACV3P+*. Single point calculations of LACV3P+* on LACVP optimised geometries.

\begin{tabular}{|c|c|c|c|c|c|c|c|c|c|c|c|c|c|}
\hline State & $\Delta E^{\mathrm{a}}$ & $\rho_{\mathrm{Fe}}$ & $\rho_{\mathrm{O}}$ & $\rho_{\text {Por }}$ & $\rho_{\mathrm{ImH}}$ & $\rho_{\text {Asp }}$ & $\rho_{\text {Trp }}$ & $Q_{\mathrm{Fe}}$ & $Q_{\mathrm{O}}$ & $Q_{\text {Por }}$ & $Q_{\mathrm{ImH}}$ & $Q_{\text {Asp }}$ & $Q_{\operatorname{Trp}}$ \\
\hline${ }^{4} \mathrm{~A}_{2 \mathrm{u}}{ }^{\mathrm{b}}$ & 0.00 & 1.08 & 0.99 & 0.42 & 0.00 & 0.01 & 0.50 & 0.50 & -0.15 & -0.21 & 0.22 & -0.78 & 0.42 \\
\hline${ }^{2} A_{2 u} b$ & 0.05 & 1.13 & 0.97 & -0.56 & -0.03 & 0.00 & -0.51 & 0.50 & -0.16 & -0.21 & 0.22 & -0.78 & 0.43 \\
\hline${ }^{3} \Pi$ & $-94.77^{c}$ & 1.14 & 0.95 & -0.07 & -0.02 & 0.00 & 0.00 & 0.52 & -0.18 & -0.88 & 0.43 & -0.86 & -0.03 \\
\hline
\end{tabular}

${ }^{a}$ in kcal mol ${ }^{-1} \cdot{ }^{b}$ Orbital occupation: $\pi^{*}{ }_{\mathrm{xz}}{ }^{1} \pi^{*}{ }_{\mathrm{yz}}{ }^{1}\left(\mathrm{a}_{2 \mathrm{u}}+\pi_{\mathrm{Trp}}\right)^{1} \cdot{ }^{c}-94.77 \mathrm{kcal} \mathrm{mol}^{-1}=4.11 \mathrm{eV}$. 
Table S3. Relative energies, group spin densities $(\rho)$ and group charges $(Q)$ of low-lying electronic states of $\mathrm{Cpd}$ I and $\mathrm{Cpd}$ II of $\mathrm{C} c \mathrm{P}$ under the influence of a dielectric constant of $\varepsilon=5.7$ as calculated with Jaguar using UB3LYP/LACVP.

\begin{tabular}{|c|c|c|c|c|c|c|c|c|c|c|c|c|c|}
\hline State & $\Delta E_{\varepsilon=5.7}{ }^{\mathrm{a}}$ & $\rho_{\mathrm{Fe}}$ & $\rho_{\mathrm{O}}$ & $\rho_{\text {Por }}$ & $\rho_{\mathrm{ImH}}$ & $\rho_{\text {Asp }}$ & $\rho_{\text {Trp }}$ & $Q_{\mathrm{Fe}}$ & $Q_{\mathrm{O}}$ & $Q_{\text {Por }}$ & $Q_{\mathrm{ImH}}$ & $Q_{\text {Asp }}$ & $Q_{\operatorname{Trp}}$ \\
\hline${ }^{4} \mathrm{~A}_{2 \mathrm{u}}{ }^{\mathrm{b}}$ & 0.00 & 1.08 & 0.98 & 0.48 & 0.00 & 0.00 & 0.46 & 0.61 & -0.34 & -0.05 & 0.18 & -0.70 & 0.30 \\
\hline${ }^{2} \mathrm{~A}_{2 \mathrm{u}}{ }^{\mathrm{b}}$ & 0.15 & 1.11 & 0.97 & -0.58 & -0.03 & 0.00 & -0.47 & 0.61 & -0.34 & -0.07 & 0.18 & -0.70 & 0.32 \\
\hline${ }^{4} \mathrm{~A}_{1 \mathrm{u}}$ & 5.27 & 1.07 & 1.00 & 0.62 & -0.01 & 0.00 & 0.32 & 0.61 & -0.33 & 0.07 & 0.17 & -0.72 & 0.20 \\
\hline${ }^{2} \mathrm{~A}_{1 \mathrm{u}}$ & 3.72 & 1.08 & 0.99 & -0.55 & -0.01 & 0.00 & -0.51 & 0.61 & -0.34 & -0.08 & 0.16 & -0.71 & 0.36 \\
\hline${ }^{3} \Pi$ & $-110.12^{c}$ & 1.15 & 0.92 & -0.06 & -0.01 & 0.00 & 0.00 & 0.60 & -0.38 & -0.53 & 0.16 & -0.74 & -0.11 \\
\hline
\end{tabular}

${ }^{a}$ in kcal mol ${ }^{-1} \cdot{ }^{b}$ Orbital occupation: $\pi^{*}{ }_{\mathrm{xz}}{ }^{1} \pi_{\mathrm{yz}}^{*}{ }^{1}\left(\mathrm{a}_{2 \mathrm{u}}+\pi_{\mathrm{Trp}}\right)^{1} .{ }^{c}-110.12 \mathrm{kcal} \mathrm{mol}^{-1}=4.78 \mathrm{eV}$.

Table S4. Relative energies, group spin densities $(\rho)$ and group charges $(Q)$ of low-lying electronic states of Cpd I and Cpd II of CcP under the influence of a dielectric constant of $\varepsilon=10.65$ as calculated with Jaguar using UB3LYP/LACVP.

\begin{tabular}{|c|c|c|c|c|c|c|c|c|c|c|c|c|c|}
\hline State & $\Delta E_{\varepsilon=10.65^{\mathrm{a}}}$ & $\rho_{\mathrm{Fe}}$ & $\rho_{\mathrm{O}}$ & $\rho_{\text {Por }}$ & $\rho_{\mathrm{ImH}}$ & $\rho_{\text {Asp }}$ & $\rho_{\text {Trp }}$ & $Q_{\mathrm{Fe}}$ & $Q_{\mathrm{O}}$ & $Q_{\text {Por }}$ & $Q_{\mathrm{ImH}}$ & $Q_{\text {Asp }}$ & $Q_{\operatorname{Trp}}$ \\
\hline${ }^{4} \mathrm{~A}_{2 \mathrm{u}}{ }^{\mathrm{b}}$ & 0.00 & 1.10 & 0.96 & 0.48 & 0.00 & 0.00 & 0.46 & 0.61 & -0.36 & -0.03 & 0.18 & -0.70 & 0.30 \\
\hline${ }^{2} \mathrm{~A}_{2 \mathrm{u}}{ }^{\mathrm{b}}$ & 0.11 & 1.13 & 0.95 & -0.57 & -0.03 & 0.00 & -0.48 & 0.61 & -0.36 & -0.05 & 0.18 & -0.70 & 0.32 \\
\hline${ }^{4} \mathrm{~A}_{1 \mathrm{u}}$ & 4.94 & 1.08 & 0.98 & 0.63 & -0.01 & 0.00 & 0.32 & 0.61 & -0.35 & 0.09 & 0.17 & -0.72 & 0.20 \\
\hline${ }^{2} \mathrm{~A}_{1 \mathrm{u}}$ & 3.51 & 1.10 & 0.98 & -0.56 & -0.01 & 0.00 & -0.51 & 0.61 & -0.35 & -0.09 & 0.17 & -0.71 & 0.37 \\
\hline${ }^{3} \Pi$ & $-113.07^{c}$ & 1.15 & 0.92 & -0.06 & -0.01 & 0.00 & 0.00 & 0.59 & -0.39 & -0.50 & 0.16 & -0.75 & -0.11 \\
\hline
\end{tabular}

${ }^{a}$ in kcal mol ${ }^{-1} .{ }^{b}$ Orbital occupation: $\pi^{*}{ }_{\mathrm{xz}}{ }^{1} \pi^{*}{ }_{\mathrm{yz}}{ }^{1}\left(\mathrm{a}_{2 \mathrm{u}}+\pi_{\mathrm{Trp}}\right)^{1} \cdot{ }^{c}-113.07 \mathrm{kcal} \mathrm{mol}^{-1}=4.90 \mathrm{eV}$. 
Table S5. Relative energies, group spin densities $(\rho)$ and group charges $(Q)$ of low-lying electronic states of Cpd I of $\mathrm{C} c \mathrm{P}$ with an extra point charge of $Q=+1$ put in the coordinates of the $\mathrm{Na}$ atom in 1OAF.pdb with respect to iron-imidazole group as calculated with Gaussian-98 using UB3LYP/LACVP.

\begin{tabular}{|c|c|c|c|c|c|c|c|c|c|c|c|c|c|}
\hline State & $\Delta E_{Q=+1}^{\mathrm{a}}$ & $\rho_{\mathrm{Fe}}$ & $\rho_{\mathrm{O}}$ & $\rho_{\text {Por }}$ & $\rho_{\mathrm{ImH}}$ & $\rho_{\text {Asp }}$ & $\rho_{\text {Trp }}$ & $Q_{\mathrm{Fe}}$ & $Q_{\mathrm{O}}$ & $Q_{\text {Por }}$ & $Q_{\mathrm{ImH}}$ & $Q_{\text {Asp }}$ & $Q_{\operatorname{Trp}}$ \\
\hline${ }^{4} \mathrm{~A}$ & 0.00 & 1.00 & 1.06 & 0.75 & 0.01 & 0.01 & 0.17 & 0.61 & -0.25 & 0.15 & 0.16 & -0.67 & 0.00 \\
\hline${ }^{2} \mathrm{~A}$ & 0.48 & 1.03 & 1.05 & -0.87 & -0.03 & -0.01 & -0.17 & 0.61 & -0.25 & 0.15 & 0.16 & -0.67 & 0.00 \\
\hline
\end{tabular}

a. in $\mathrm{kcal} \mathrm{mol}^{-1}$.

Table S6. Relative energies, group spin densities $(\rho)$ and group charges $(Q)$ of low-lying electronic states of $\mathrm{Cpd}$ I of $\mathrm{C} c \mathrm{P}$ with an extra point charge of $Q=-1$ put in the coordinates of the Na atom in 1OAF.pdb with respect to iron-imidazole group as calculated with Gaussian-98 using UB3LYP/LACVP.

\begin{tabular}{|c|c|c|c|c|c|c|c|c|c|c|c|c|c|}
\hline State & $\Delta E_{Q=-1}^{\mathrm{a}}$ & $\rho_{\mathrm{Fe}}$ & $\rho_{\mathrm{O}}$ & $\rho_{\text {Por }}$ & $\rho_{\mathrm{ImH}}$ & $\rho_{\text {Asp }}$ & $\rho_{\text {Trp }}$ & $Q_{\mathrm{Fe}}$ & $Q_{\mathrm{O}}$ & $Q_{\text {Por }}$ & $Q_{\mathrm{ImH}}$ & $Q_{\text {Asp }}$ & $Q_{\text {Trp }}$ \\
\hline $\begin{array}{l}{ }^{4} \mathrm{~A} \\
{ }^{2} \mathrm{~A}\end{array}$ & 0.00 & 1.03 & 1.03 & 0.11 & 0.00 & 0.01 & 0.82 & 0.62 & -0.29 & -0.47 & 0.17 & -0.68 & 0.65 \\
\hline${ }^{2} \mathrm{~A}$ & -0.26 & 1.06 & 1.02 & -0.23 & -0.02 & -0.01 & -0.82 & 0.62 & -0.29 & -0.47 & 0.17 & -0.68 & 0.65 \\
\hline
\end{tabular}

a. in $\mathrm{kcal} \mathrm{mol}^{-1}$. 


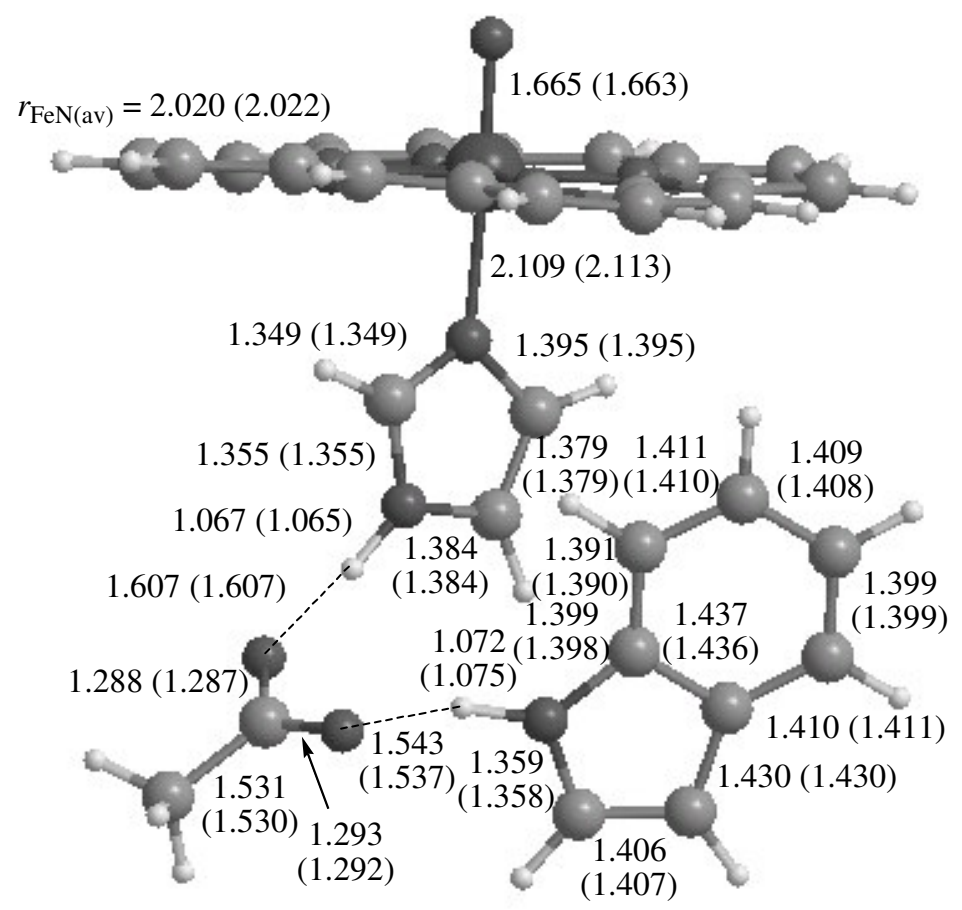

${ }^{4} \mathrm{~A}_{2 \mathrm{u}}\left({ }^{2} \mathrm{~A}_{2 \mathrm{u}}\right)$

Figure S1. Optimized geometries of the lowest quartet (doublet) states of Cpd I of CcP. All geometries were fully optimized with Jaguar and subsequent frequency analysis done with Gaussian-98 at the UB3LYP/LACVP level of theory. Bond lengths are in Ångstroms. 


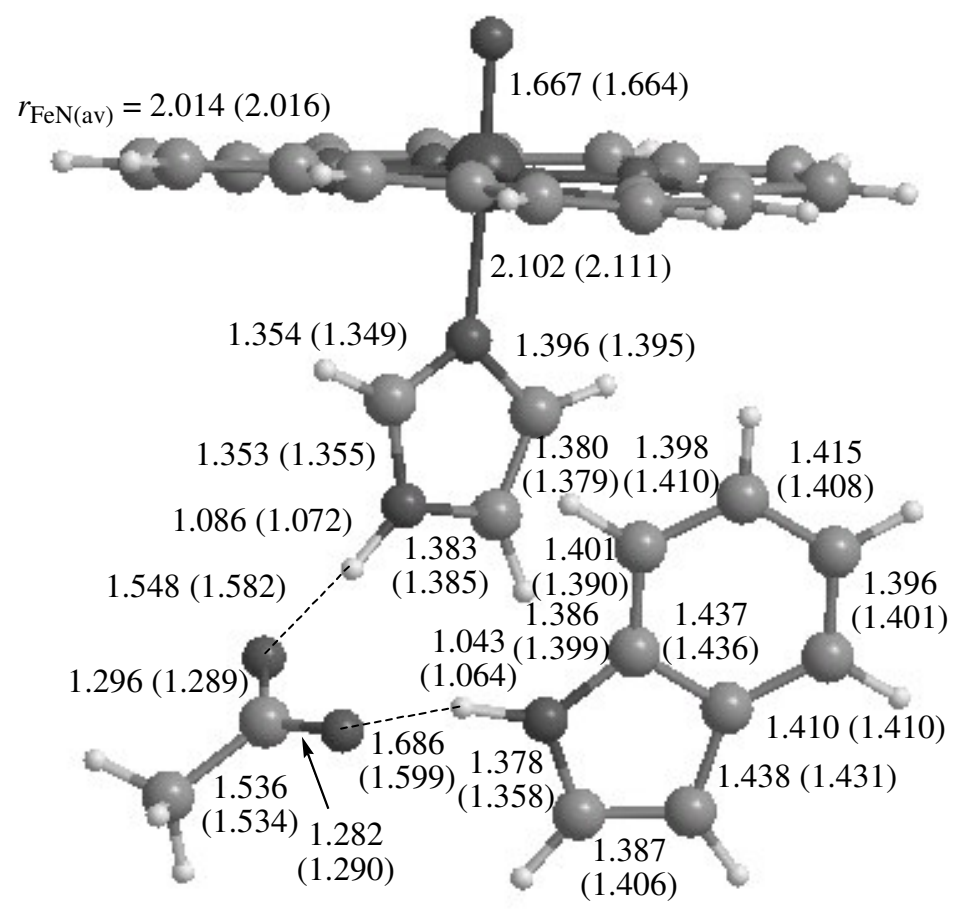

${ }^{4} \mathrm{~A}_{2 \mathrm{u}}\left({ }^{2} \mathrm{~A}_{2 \mathrm{u}}\right)$

Figure S2. Optimized geometries of $\mathrm{Cpd}$ I of $\mathrm{CcP}$ in the ${ }^{4} \mathrm{~A}_{1 \mathrm{u}}\left({ }^{2} \mathrm{~A}_{1 \mathrm{u}}\right)$ states. All geometries full optimized with Jaguar at the UB3LYP/LACVP level of theory. All bond lengths are in Angstroms. 


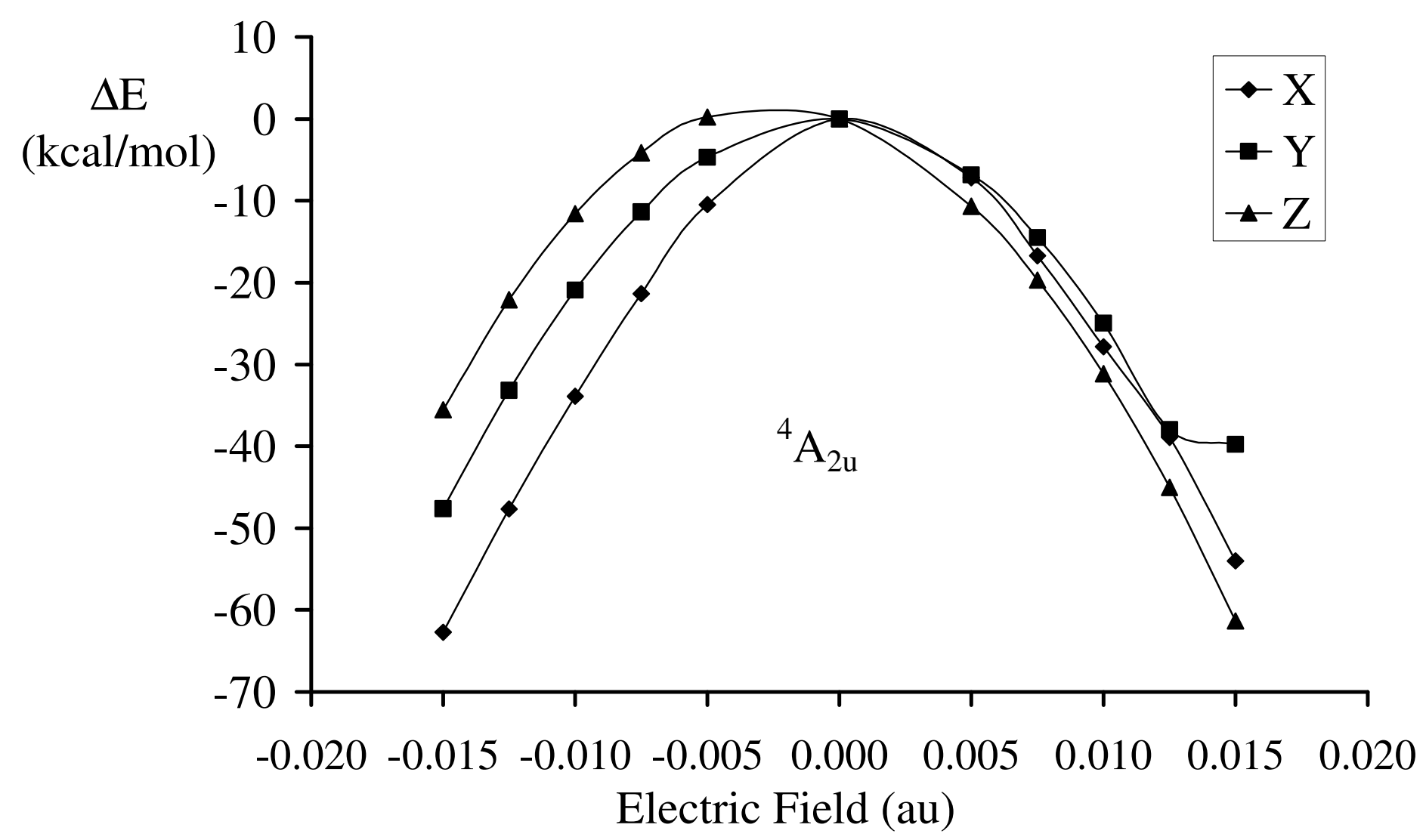

Figure S3. Relative energies of the lowest lying quartet spin state with the addition of an electric field along the molecular $x$-, $y$-, or $z$-axis (as defined in Figure 5 of the main text). All energies are in $\mathrm{kcal} \mathrm{mol}^{-1}$ with respect of the unperturbed system. 


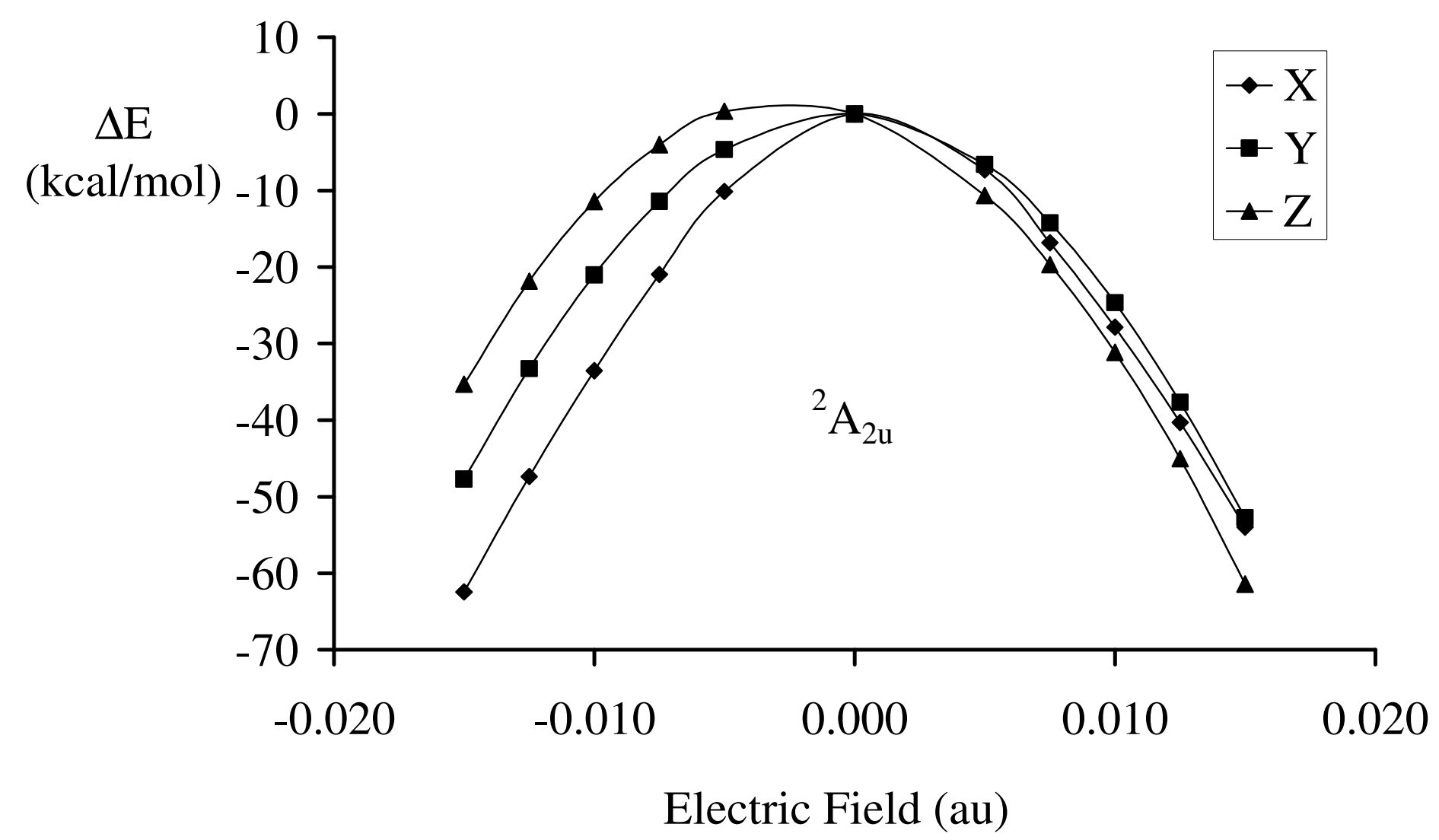

Figure S4. Relative energies of the lowest lying doublet spin state with the addition of an electric field along the molecular $x$-, $y$-, or $z$-axis (as defined in Figure 5 of the main text). All energies are in $\mathrm{kcal} \mathrm{mol}^{-1}$ with respect of the unperturbed system. 


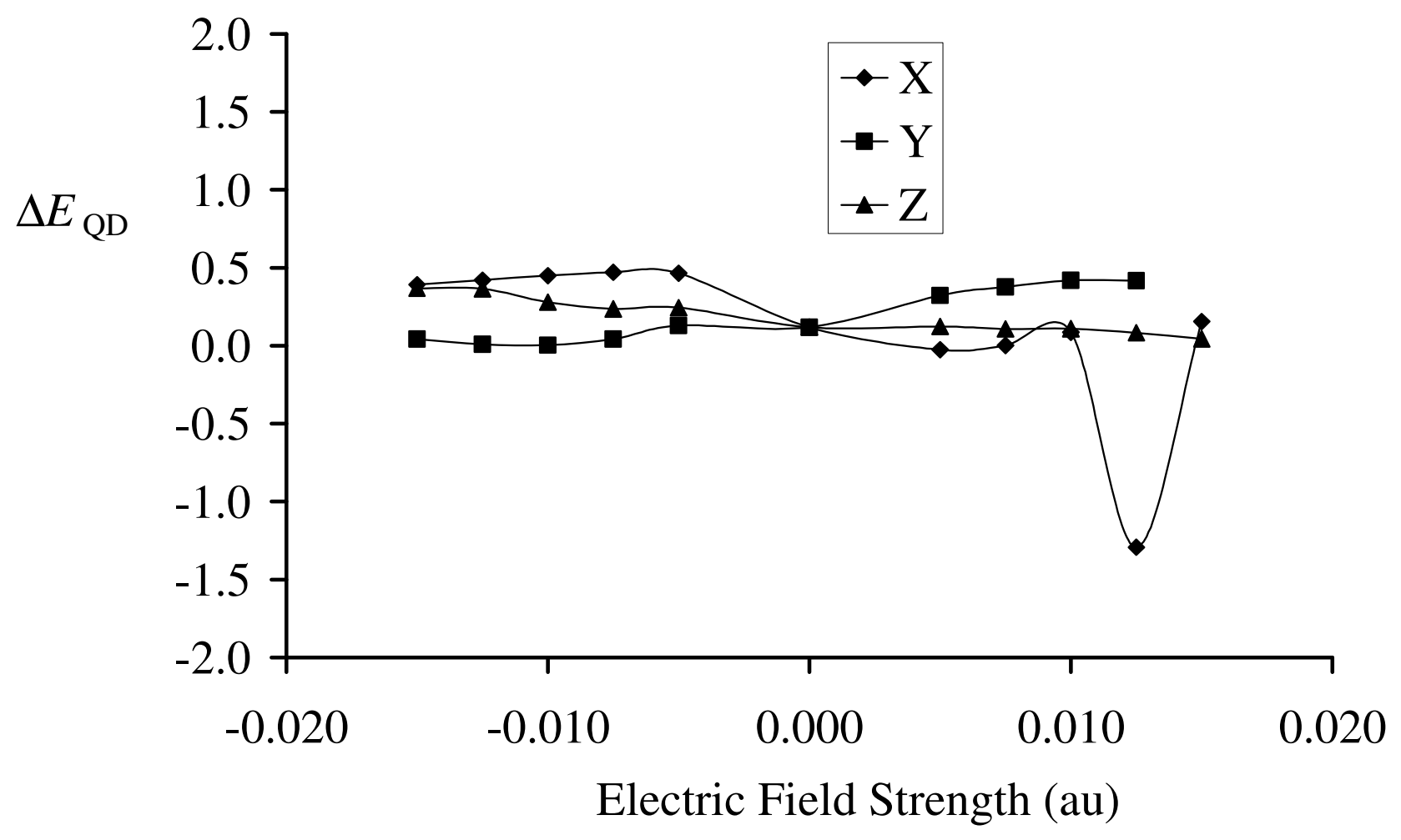

Figure S5. Quartet-doublet energy gap under the influence of an electric field along the molecular $x$-, $y$-, or $z$-axis (as defined in Figure 5 of the main text). A positive value denotes a quartet ground state; all energies are in $\mathrm{kcal} \mathrm{mol}^{-1}$. 


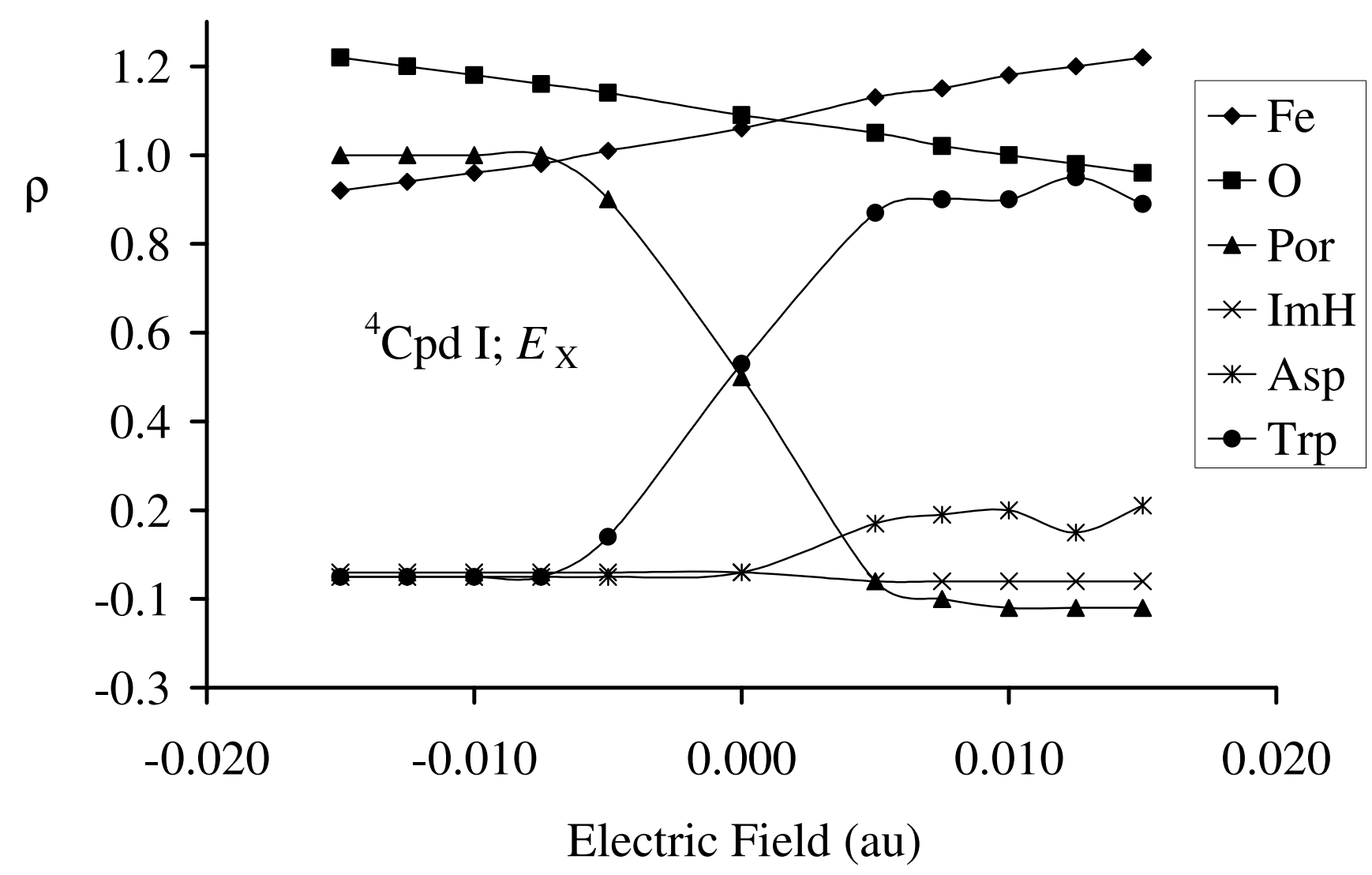

Figure S6. Group spin density changes of the lowest lying quartet spin state under the influence of an electric field along the molecular $x$-axis (as defined in Figure 5 of the main text). 


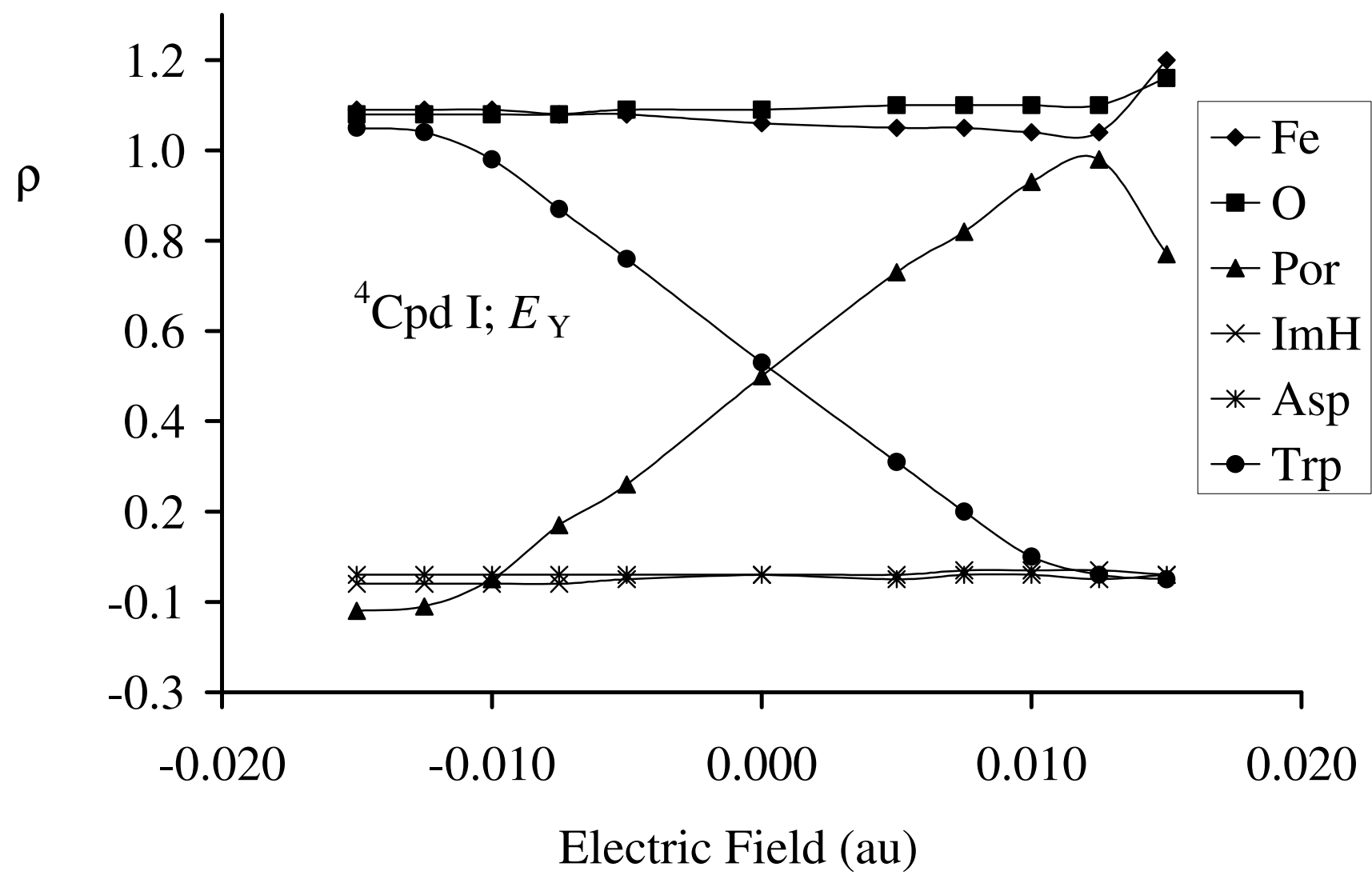

Figure S7. Group spin density changes of the lowest lying quartet state under the influence of an electric field along the molecular $y$-axis (as defined in Figure 5 of the main text). 


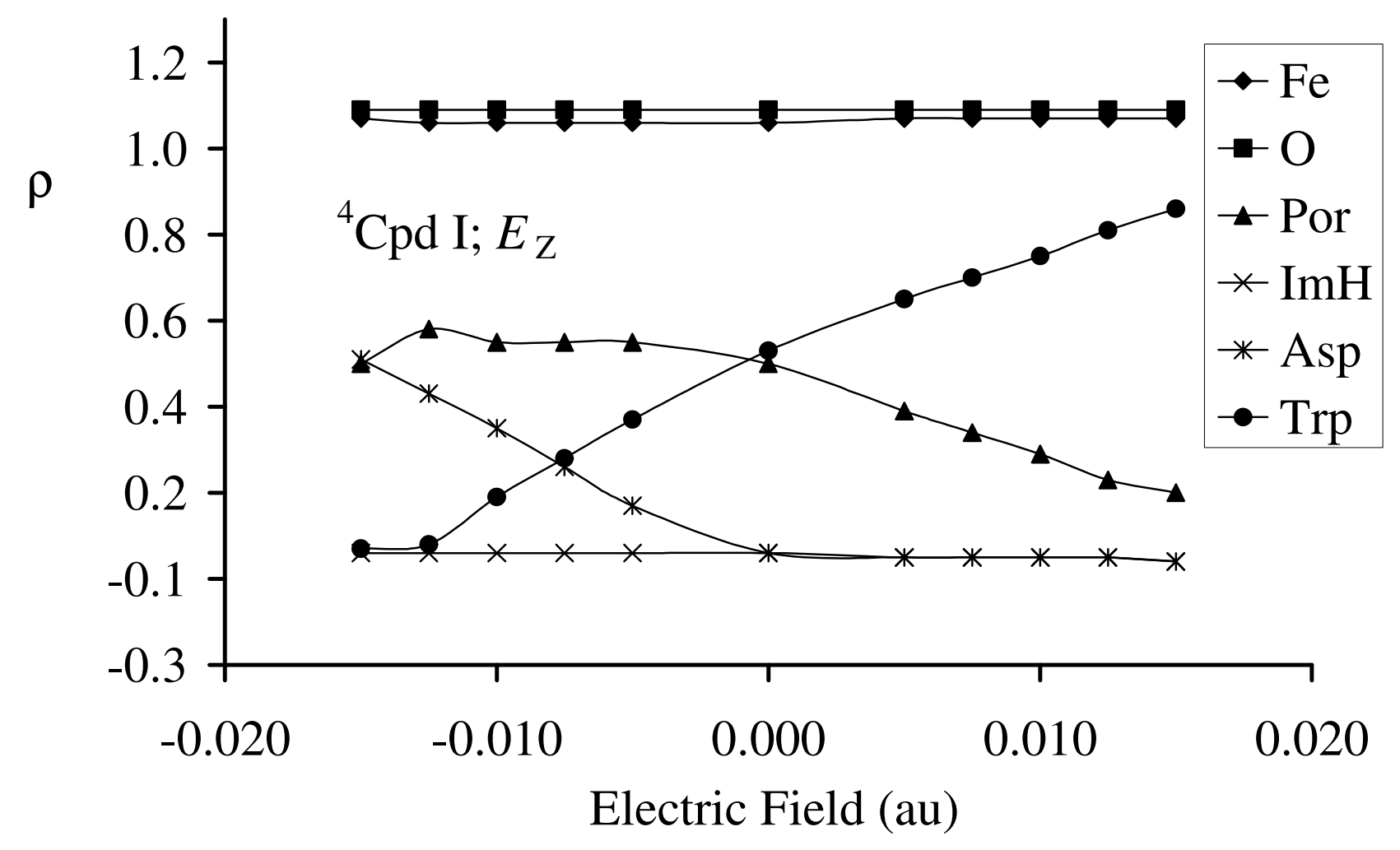

Figure S8. Group spin density changes of the lowest lying quartet spin state under the influence of an electric field along the molecular $z$-axis (as defined in Figure 5 of the main text). 


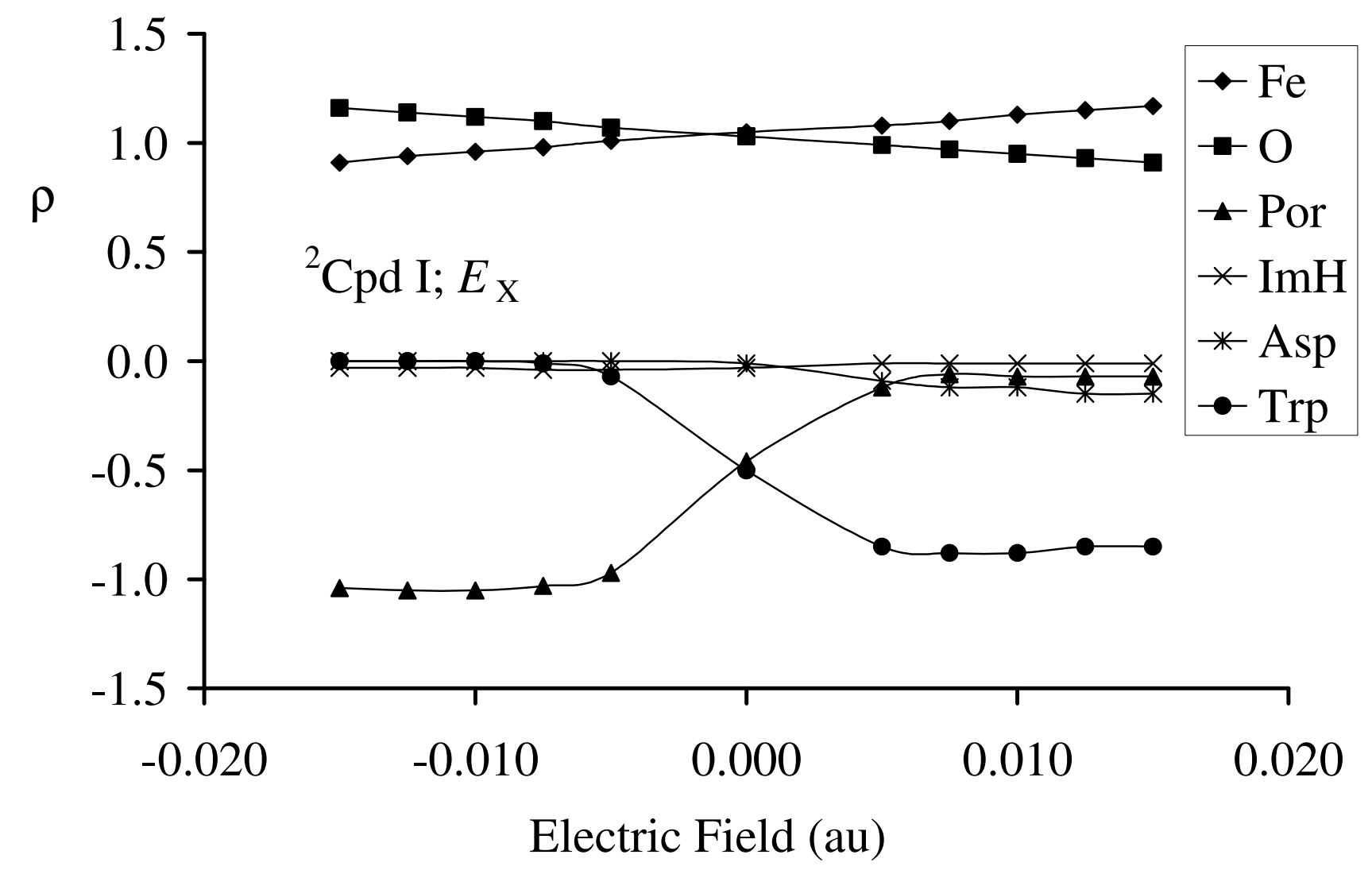

Figure S9. Group spin density changes of the lowest lying doublet spin state under the influence of an electric field along the molecular $x$-axis (as defined in Figure 5 of the main text). 


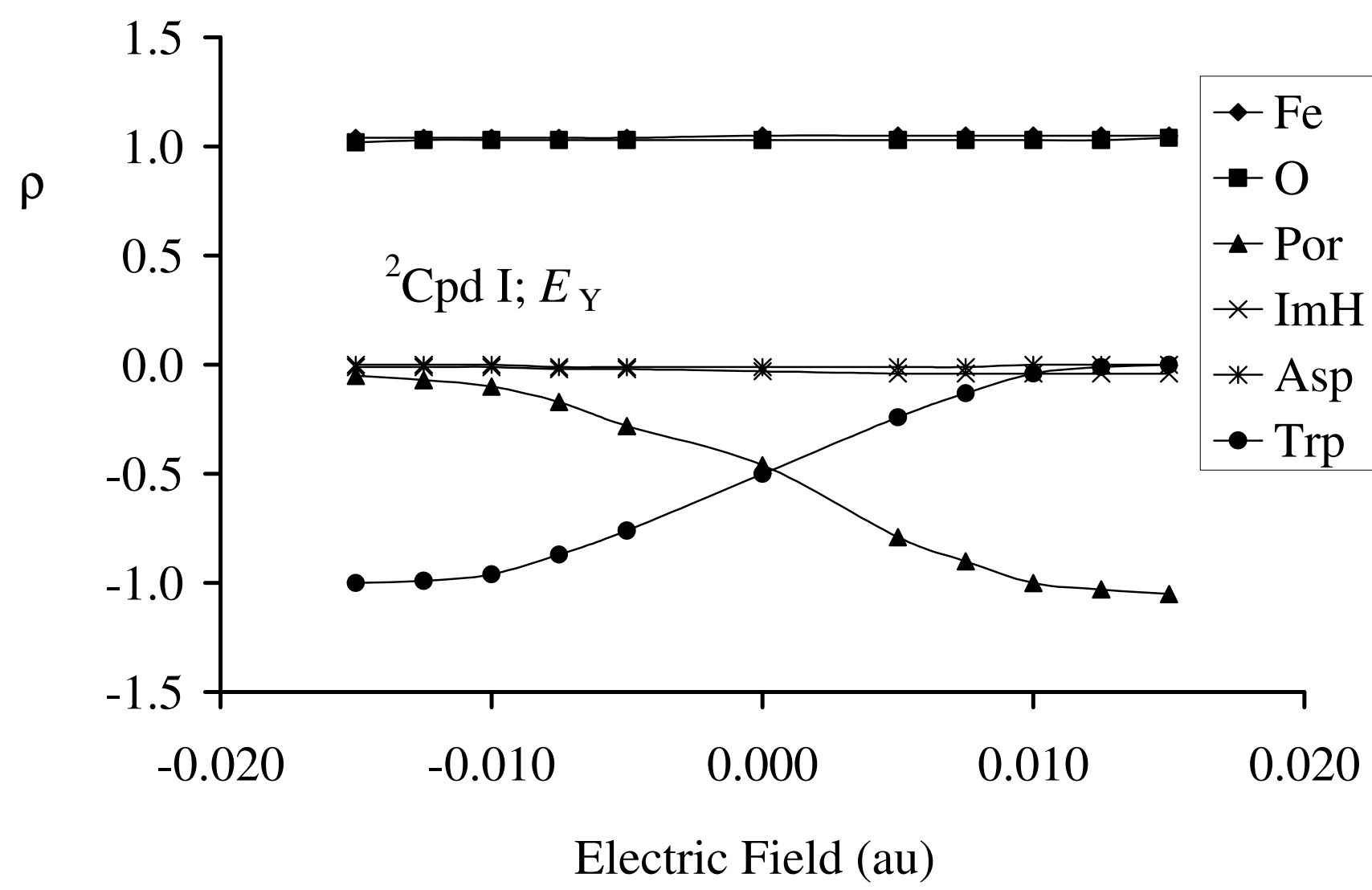

Figure S10. Group spin density changes of the lowest lying doublet spin state under the influence of an electric field along the molecular $y$-axis (as defined in Figure 5 of the main text). 


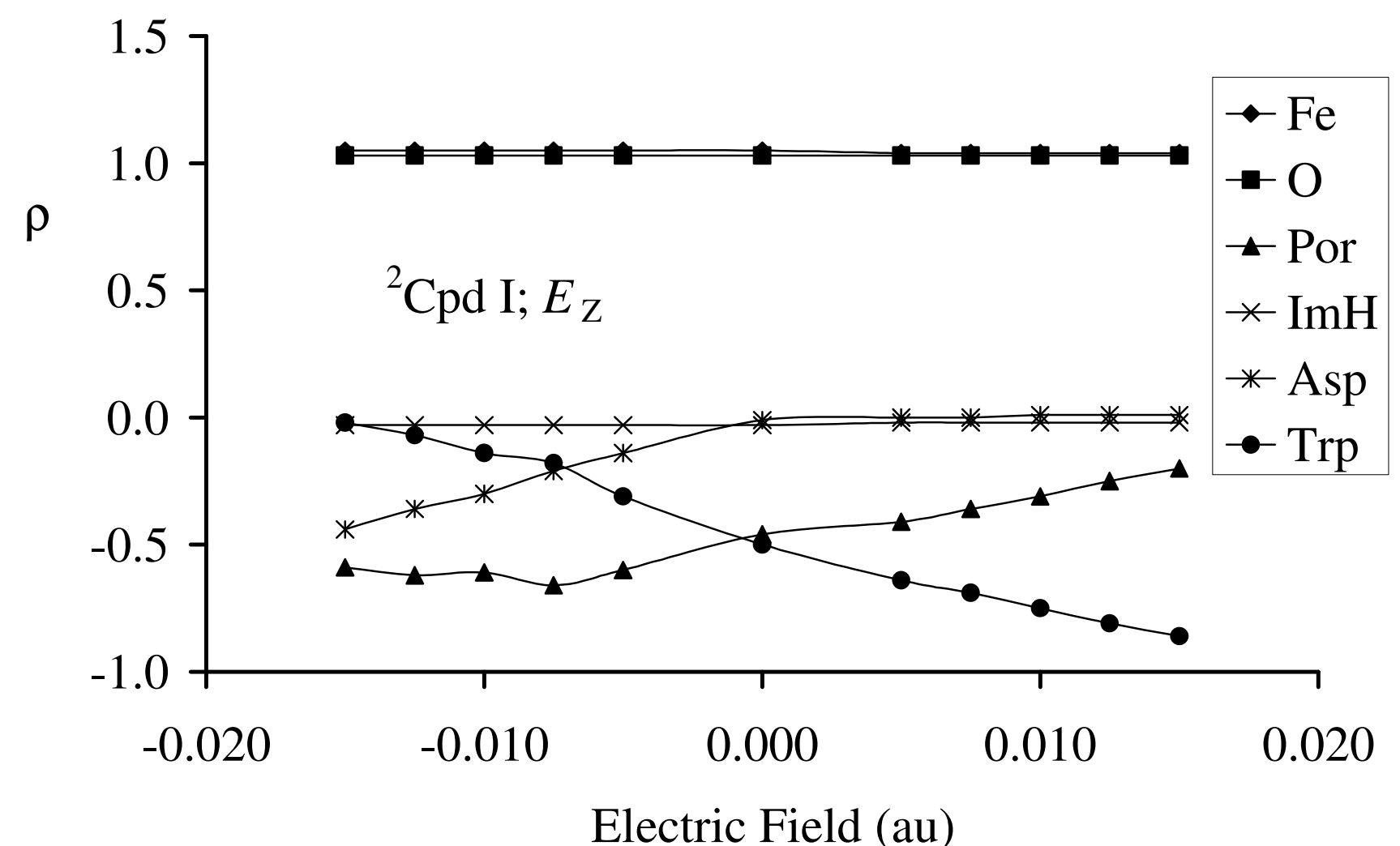

Figure S11. Group spin density changes of the lowest lying doublet spin state under the influence of an electric field along the molecular $z$-axis (as defined in Figure 5 of the main text). 